\title{
A FUNÇÃO SOCIAL DA CIDADE NA AMÉRICA LATINA: UM ESTUDO COMPARADO ENTRE BRASIL E COLÔMBIA
}

\author{
Mônica da Silva Cruz ${ }^{1}$ \\ Regina Lúcia Gonçalves Tavares ${ }^{2}$
}

\begin{abstract}
RESUMO: Busca-se compreender a função social da cidade numa perspectiva constitucional comparada entre Brasil e Colômbia, equiparando peculiaridades daqueles sistemas quanto à realização prática deste direito fundamental social. Teoricamente, parte-se das contribuições de Lefebvre sobre a dimensão humana da cidade, a partir da qual se discutirá o direito à moradia urbana como um direito fundamental. A metodologia consiste em pesquisa bibliográfica e legislativa. O corpus se constitui das Constituições do Brasil e da Colômbia. O problema que se coloca neste trabalho é: qual é o alcance prático da norma quanto à consolidação de políticas de democratização das cidades nesses países?
\end{abstract}

PALAVRAS-CHAVE: Função social da cidade; Direito à moradia; Brasil; Colômbia; Democratização dos espaços urbanos.

\section{THE CITY SOCIAL'S FUNCTION IN LATIN AMERICA: A COMPARATIVE STUDY BETWEEN BRAZIL AND COLOMBIA}

\begin{abstract}
It seeks to understand the city social's function in constitutional perspective compared between Brazil and Colombia, matching the peculiarities by those systems respecting the fundamental social right's practical realization. Theoretically, it is based on the Lefebvre's contributions about the human dimension of the city, from which the right to urban housing will be discussed as a fundamental right. The methodology consists of bibliographical and legislative research. The corpus is constituted by the Constitutions of Brazil and Colombia. The problem that arises in this work is: What's the practical scope law's scope, about democratization's policies of cities consolidation in both cities?
\end{abstract}

KEYWORDS: Social function of the city; Right to Housing; Brazil; Colombia; Democratization of urban spaces.

\footnotetext{
${ }^{1}$ Doutorado e mestrado em Lingüística e Língua Portuguesa pela Universidade Estadual Paulista Júlio de Mesquita Filho (UNESP/Araraquara). Professora adjunta, nível IV, do Departamento de Letras, Professora do Programa de Pós-Graduação em Direito e Instituições do Sistema de Justiça da Universidade Federal do Maranhão (UFMA) e Professora do Programa de Pós-Graduação em Letras. E-mail: monicasc.cruz@ig.com.br

${ }^{2}$ Mestrado em Direito e Instituições do Sistema de Justiça pela Universidade Federal do Maranhão (PGPPUFMA). Especialista em Processo Civil pela PUC/Campinas (2003). Especialista em Processo Civil pela Universidade Ceuma (2004). Advogada e Professora de Direito Processual Civil na Universidade Federal de Juiz de Fora (UFJF). E-mail: rlg.t@ hotmail.com
}

Rev. de Direito Urbanístico, Cidade e Alteridade | e-ISSN: 2525-989X | Maranhão | v. 3 | n. 2 | p. 34 - 55 | Jul/Dez. 2017. 


\section{INTRODUÇÃO}

O planeta terra vivencia uma realidade generalizada segundo a qual milhões de pessoas compartilham condições precárias de moradia, sobretudo no ambiente das cidades.

Esta é situação de grande parte dos países latino-americanos, deficitários de políticas de habitação, sobretudo quanto à definição de territorialidades e promoção de moradia, isto porque não conseguem inserir sua população, sobretudo as camadas mais pobres, nas estratégias de financeirização do acesso à terra urbana, fato que as leva a recorrer aos processos de autoconstrução, em locais improváveis, ou mesmo a amontoarem-se em cortiços e favelas.

Tal realidade influencia sobremaneira a formação dos espaços urbanos, implicando numa conjuntura de segregação que se repete em várias cidades e, por isto, finda por criar espaços privilegiados que se opõem a cinturões de pobreza nos quais é negada aos seus habitantes a função social da cidade, entendida nesta pesquisa como premissa que legitima e orienta a Política Urbana, cuja tarefa é a de, segundo Jordi Borja (2003) integrar, física e simbolicamente, o indivíduo na cidade.

Com base nos problemas de déficit de moradia vivenciado pelas grandes cidades da América Latina (MARICATO, 2013), localizam-se desafios semelhantes no contexto da política urbana, compartilhados pelo Brasil e pela Colômbia, os dois países mais populosos da América do $\mathrm{Sul}^{3}$, o que se põe aqui como justificativa para a presente pesquisa.

Naqueles dois países, prevalecem políticas habitacionais hábeis em reproduzir uma conjuntura política pela qual se preserva a hegemonia da propriedade individual a favorecer a financeirização do acesso à 'casa própria'. Trata-se, segundo Raquel Rolnik de "um longo processo de desconstrução da habitação como um bem social e de sua transmutação em mercadoria e ativo financeiro" (ROLNIK, 2015, p. 26).

Além de apresentarem um déficit de moradias que, consequentemente, desprestigiam as funções sociais da cidade ${ }^{4}$, os dois países acima citados, paradoxalmente, têm em comum,

\footnotetext{
${ }^{3}$ A projeção populacional brasileira até 2017 contabiliza 206.122.615 habitantes; no caso da Colômbia, até 2011, contabilizou uma estimativa, até 2016, de 48.929.706 habitantes. (WIKIPÉDIA, 2017)

${ }^{4}$ Conforme pesquisa empreendida pelo Banco Interamericano de Desenvolvimento, 33\% das famílias, no Brasil, são sem-teto, ou residem em moradias inadequadas (BID, 2012). Na Colômbia, o Ministerio de Vivienda, Ciudad y Territorio, a quem cabe a administração do setor de habitação e demais políticas urbanas de moradia, cujo papel é de enfrentar um déficit habitacional urbano, informa um número deficitário, estimado até 2013, de 14,9\%, ou seja, 1.523.484 de moradias (493.805 de déficit quantitativo e 1.303.043 de déficit qualitativo). (COLÔMBIA, 2014)
}

Rev. de Direito Urbanístico, Cidade e Alteridade | e-ISSN: 2525-989X | Maranhão | v. 3 | n. 2 | p. 34 - 55 | Jul/Dez. 2017. 
Constituições nas quais aquele direito é afirmado como uma garantia fundamental do cidadão, um direito de natureza social.

Por esta razão, a intenção do presente trabalho é, além de compreender as funções sociais da cidade, numa perspectiva constitucional comparada, esmiuçar suas características no cenário legislativo do Brasil e da Colômbia, colacionando suas peculiaridades no que diz respeito à proteção e aplicação imediata dos direitos sociais, frente a uma realidade de distorções.

Neste propósito, a partir de uma perspectiva comparatista, o trabalho buscará relacionar ambos os ordenamentos jurídicos, estudando-os em suas respectivas conjunturas históricas e políticas para, assim, cotejar pontos de similitude e diferenciação em suas ordens normativas.

Tomando-se o marco jurídico da Constituição de 1988, no caso do Brasil, e da Constituição de 1991, no caso da Colômbia, vai-se a analisar os desafios contemporâneos da questão urbana tomando-se como ponto de análise a função social da cidade, esta reconhecida como um princípio qualificante do direito social à moradia, para efeito de se acarearem as necessidades urbanas básicas daquelas duas realidades.

Assim relacionados o direito à moradia e a função social da cidade, vai-se, na esteira do pensamento de Milton Santos (2012), compreendendo os processos de urbanização e acesso à moradia digna como práticas públicas postas a serviço do mercado global, numa estratégia política nominada pelo autor de "especialização funcional”, segundo a qual o desenvolvimento urbano está diretamente ligado ao desenvolvimento industrial: Resulta daí a negação do direito à moradia e do direito à cidade a partir da falta de regularidade na qualidade do tecido urbano (BORJA, 2003), em prejudicialidade às funções sociais da cidade.

Em contrapartida, aos que não se acham integrados aos mecanismos hegemônicos de acesso à moradia urbana e consequentemente às funções da cidade e, por isto, vulneráveis, desfiliados (CASTEL, 1998) ou mesmo descreditados do mercado de habitação, a estes restam habilitarem-se no rol de clientes de programas de habitação que, ao seu turno, na realidade social e urbanística da América Latina, têm se mostrado insuficientes, inadequados e condescendentes com as políticas globais de mercado (MARICATO, 2013). Tal realidade posta em pauta torna clara uma deficiência no cumprimento da função social da cidade, o que finda por revelar o grande desafio posto à norma que prevê sua materialização como uma garantia fundamental, o que doravante se abordará limitando-se ao contexto do Brasil e da Colômbia. 
O referencial teórico mobilizado se sustenta nos estudos de direito à moradia e à cidade (LEFEBVRE, 2011; MARICATO, 2013; SANTOS, 2012; ROLNIK, 2015; HARVEY, 2014, dentre outros) e de sua função social enquanto direito fundamental (ALVIM, 214; CHINCHILLA HERRERA, 2009; ESCRIVÃO FILHO e SOUSA JÚNIOR, 2016; e STRECK, 2014, além de outros), numa abordagem comparatista entre as realidades constitucionais do Brasil e da Colômbia (PEGORARO e RINELLA, 2006; SHAPIRO, 2004).

A metodologia é organizada a partir de pesquisa bibliográfica e legislativa; as análises são de base qualitativa e o corpus se constitui das Constituições do Brasil e da Colômbia.

Alinhavando as semelhanças e diferenças da trama constitucional da Colômbia e do Brasil, constituída a partir da analogia do processo de redemocratização de ambos os países, torna-se possível empreender uma aproximação ontológica de suas disposições constitucionais que, em comum, optaram pela previsão exaustiva de um rol de direitos e garantias fundamentais.

Por outro lado, esta comparação se torna operativa na medida em que as equivalências encontradas em ambos os textos constitucionais, flagrantemente opostas à realidade social dos dois países, evidenciam uma conjuntura política sob a qual o direito urbanístico é decifrado a partir de uma pauta empresarial, o que permite refletir sobre o seguinte problema: qual é o alcance prático da norma constitucional que dispõe sobre a consolidação de políticas de democratização e funcionalização social das cidades?

\section{AS FUNÇÕES SOCIAIS DA CIDADE NUMA PERSPECTIVA CONSTITUCIONAL COMPARADA}

Para Norbert Rouland, “o direito pertence ao que os antropólogos denominam a cultura: o que o homem constrói a partir do dado natural que lhe é imposto" (ROULAND, 2008, p. 36), porquanto, partindo-se deste pressuposto, é possível entender que, ao mesmo tempo em que o direito é estruturante para o nascimento do homem social, especialmente no que tange a sua natural inclinação para viver em grupo, do mesmo modo, também é contingente de seu artifício em buscar fórmulas para equacionar suas escolhas e relações: "a invenção dessas relações supõe o emprego de raciocínios e de mecanismos que hoje qualificamos de jurídicos" (ROULAND, 2008, p. 41). O Direito à Cidade é um raciocínio, ou mecanismo que, embrionariamente, decorre desta lógica que se origina a partir da especialização dos espaços de habitação.

Rev. de Direito Urbanístico, Cidade e Alteridade | e-ISSN: 2525-989X | Maranhão | v. 3 | n. 2 | p. 34 - 55 | Jul/Dez. 2017. 
Raquel Rolnik entende a cidade como uma estrutura magnética, um campo de atração que reúne e concentra (ROLNIK, 2014, p. 13), do qual brotam as noções de coletividade e de político, já que, por sua essência agregadora, demanda, ontologicamente, a necessidade de organização, de regras e de regulamentos para sua sobrevivência.

Trata-se da dimensão política da cidade, concebida em sua capacidade de proteger, juntar e constranger, exercitada mediante uma autoridade político-administrativa em relação ao espaço e aos seus habitantes (ROLNIK, 2014, p. 26), cuja feição se relaciona, dialeticamente, com outras dimensões das cidades, tais como a econômica, a cultural, a urbanística, etc.

Por conseguinte, o crescimento populacional, tomado a partir da dimensão econômica da urbe e da competição que lhe é traço peculiar, porque agrega forças que se antagonizam, seria uma das razões pelas quais o filósofo e sociólogo francês, Henri Lefebvre (20110), recomenda a necessidade de se pensar o urbano e o homem inseridos nesta realidade.

Um novo humanismo que rejeita, segundo o citado autor, o paradigma dos limites e privações, típico da sociedade rural que, para o autor, paradoxalmente, ainda predomina sobre a configuração do urbano. Requer, por conseguinte, a descaracterização da utopia, até então mimetizada em um positivismo estéril que, na sua visão, impediria o exercício dialógico da experiência de se estudarem as implicações e consequências dos modelos de vida urbana e dos "sistemas de significações 5 " que conformam o habitar.

Em outras palavras, de concebe-se uma ciência da cidade a partir de estratégias que assumam as variáveis ligadas a questão urbana (LEFEBVRE, 2011), especialmente no que toca a sua dimensão humana.

A dimensão humana da cidade, entretanto, tem dado lugar a outras ideologias ou estratégias de planejamento, ligadas intrinsecamente às questões de mercado, em detrimento da conformação democrática dos espaços urbanos e da função social da cidade, com isto comprometido o enfrentamento humanitário de demandas ligadas à densidade populacional e aos equipamentos de fruição da cidade ${ }^{6}$.

\footnotetext{
${ }^{5}$ Para o autor, "os sistemas de significações do habitante diz das suas passividades e das suas atividades; é recebido, porém modificado pela prática. É percebido." (LEFEBVRE, 2011, p. 111)

${ }^{6}$ Neste sentido, o arquiteto dinamarquês Jan Gehl, em sua obra de referência sobre urbanismo e o uso dos espaços públicos, confere proeminência à dimensão humana no planejamento das cidades: "Pela primeira vez na história, logo depois da virada do milênio, a maior parte da população global é urbana e não rural. As cidades cresceram rapidamente, e o crescimento urbano vai continuar acelerado nos próximos anos. Tanto as cidades existentes como as novas terão que fazer mudanças cruciais em relação aos pressupostos para o planejamento e suas prioridades. Deve-se destacar, como objetivo-chave para o futuro, um maior foco sobre as necessidades das pessoas que utilizam as cidades" (GEHL, 2015, p. 06)
} 
Basta abrir os olhos para compreender a vida cotidiana daquele que corre de sua moradia para a estação mais próxima ou distante, para o metrô superlotado, para o escritório ou para a fábrica, para retornar à tarde o mesmo caminho e voltar para casa a fim de recuperar as forças para recomeçar tudo no dia seguinte. O quadro dessa miséria generalizada não poderia deixar de se fazer acompanhar pelo quadro das "satisfações" que a dissimulam e que se tornam os meios de elidi-la e de evadir-se dela. (LEFEBVRE, 2011, p. 118)

Teriam então as normas sobre política urbana, deontologicamente, esta função? Caberia às mesmas a tarefa de equacionar o humano e o mercado a partir da legitimação de "satisfações" que conformem e cristalizem a eterna luta de classes?

Estas questões podem ser ajuizadas a partir da necessidade de se pensar a cidade como um direito, o que permite a realização de um diagnóstico acerca da natureza das políticas urbanas e oportuniza a indagação a respeito de a quem elas servem ou privilegiam.

Lefebvre contextualiza a luta de classes no espaço urbano a partir de duas ordens de urgência: a moradia e o habitat versus o crescimento econômico conjugado à produção industrial, estes como indicadores de contradições estruturantes da sociedade de consumo, cujas variáveis assim antagonizam crescimento quantitativo versus desenvolvimento qualitativo (LEFEBVRE, 2011, p. 137). Neste sentido, o autor explica esta luta e contextualiza classe no contingente urbano:

\begin{abstract}
Uma nova miséria se estende, que toca principalmente o proletariado sem poupar outras camadas e classes sociais: a miséria do habitat, a miséria do habitante submetido a uma cotidianidade organizada (na e pela sociedade burocrática de consumo dirigido). Para aqueles que duvidam de sua existência como classe, a segregação e a miséria de seu "habitar" designam na prática a classe operária. (LEFEBVRE, 2011, p. 138)
\end{abstract}

É exatamente neste contexto que o Direto à Cidade se projeta como um lugar de articulação e discussão no campo das fraturas situadas nas contradições inerentes à luta pela gestão e fruição dos espaços urbanos e sua apropriação pelo capital financeiro: a inevitável luta entre o contingente humano e as reivindicações do mercado.

Para Lefebvre, o Direito à Cidade "se afirma como um apelo, como uma exigência" (LEFEBVRE, 2011, p. 117) de um direito à vida urbana, inevitavelmente relacionada a uma cotidianidade ordenada, a serviço de interesses cujas fontes serão problematizadas sob uma ótica comparatista, a se exercer entre dois sistemas jurídicos: o do Brasil e o da Colômbia.

A tarefa ora proposta no presente artigo é, valendo-se do modelo comparativo, estabelecer uma conexão entre aquelas duas realidades, partindo de similitudes que aproximam as duas amostras: “o 'submercado' e a produção doméstica de moradias constituem uma 
característica crucial e estrutural da produção do ambiente construído no Brasil e na América do Sul." (MARICATO, 2013, p. 86).

Far-se-á uma abordagem teórica a partir dos ordenamentos constitucionais codificados do Brasil e da Colômbia, organizando sistematicamente o conhecimento daquelas duas ordens jurídicas acerca do direito à cidade em sua feição constitucional, a partir da similitude ou dos desvios achados em tipos jurídicos comuns que anunciam a função social da cidade.

Com o objetivo de ultrapassar a mera exposição paralela daqueles dois sistemas, busca-se aqui relacioná-los, sob uma perspectiva mais universal acerca de suas características, permitindo assim a discussão das experiências vividas em ambas as realidades.

\subsection{O Direito Comparado como instrumento de significação da função social da cidade}

Mais do que a exposição sistemática do Direito, a perspectiva comparatista deve atentar para as conexões adequadas entre o conjunto de ordenamentos descritos, não se limitando exclusivamente ao cotejo da norma, mas ao contexto social que determina o surgimento das regras analisadas, como importante área de significação, a possibilitar a conjugação de soluções jurídicas que intensifiquem as relações políticas, econômicas, sociais e culturais entre sistemas distintos (PEGORARO; RINELLA, 2006).

Vale-se do comparatismo com o objetivo de formular questionamentos acerca das funções sociais da cidade no âmbito das Constituições do Brasil e da Colômbia, com desígnios práticos de intercambiar experiências e conhecimentos, o que requer um trajeto metodológico específico.

Busca-se, no corpus legislativo analisado, qual seja a Constituição do Brasil e a Constituição da Colômbia, encontrar orientações ou caminhos a serem percorridos, no intento de possibilitar uma eficiente mediação entre os sistemas jurídicos estudados e, consequentemente, a adaptação do direito interno.

Ressalte-se que a importância do estudo comparado ora proposto se manifesta a partir da constatação de que ambos os sistemas ora identificados, Brasil e Colômbia, países limítrofes da América do Sul, estão inseridos no mesmo contexto de concentração de riquezas e demandam por alternativas urbanas de produção democrática da cidade.

O estudo partirá das diferenças entre os modelos estudados, distinguindo, neste propósito, se tais diferenças tem caráter fundamental, ou mesmo acidental. Por conseguinte, serão relacionadas tais dessemelhanças, a fim de que, encontradas suas possibilidades de 
existência, sejam pontuados seus méritos e seus deméritos (GUTTERIDGE, apud, PEGORARO; RINELLA, 2006, p. 28). Neste sentido, “a comparação tem o propósito de fazer emergir as diferenças técnicas existentes entre as diversas disciplinas nacionais do mesmo problema jurídico" (BRYCE, apud, PEGORARO; RINELLA, 2006, p. 27). (Tradução nossa).

Portanto, a técnica da comparação abarcaria a própria política legislativa, uma vez que parte do pressuposto histórico de que as contradições experimentadas pela América Latina decorrem, especialmente, da dificuldade de suas democracias adquirirem estabilidade, porque estruturalmente subdesenvolvidas, sendo este problema a raiz de muitos outros: exacerbada tensão social e aumento das desigualdades, estes potencializados pelas pressões estrangeiras (tais como da Organização Mundial de Comércio, do Banco Mundial e do FMI), que tem preponderante papel na configuração e no formato das políticas públicas adotadas neste contexto.

Em ambas as realidades, é possível distinguir um paradigma de desenvolvimento econômico que identifica a força das instituições políticas e sua correlação com a lei, o crescimento econômico e a qualidade do governo, passando inclusive pela reforma judicial, numa agenda definida pelas pressões políticas e econômicas externas e pelo sistema capitalista internacional (SHAPIRO, 2004).

São realidades inseridas em um mesmo ciclo de dependência externa, portanto comungam de uma regularidade que se sobressai e se identifica a partir de determinados padrões de tratamento da questão urbana, pelo que suficiente para identificar a escolha da Colômbia, no sentido de relacioná-la com a realidade brasileira.

\subsection{Características constitucionais do Brasil e da Colômbia}

O Brasil e a Colômbia, muito embora apresentem distinções estruturais quanto à sua forma de organização política - o Brasil um Estado Republicano Federado; a Colômbia um Estado Republicano Unitário -, tem em comum o fato de apresentarem contemporaneidade quanto ao redesenho de suas respectivas constituições.

Ambos os países reagiram quase que simultaneamente ao processo de redemocratização da América Latina, a partir do final da década de 80, que se amoldou ao longo da década de 90: o Brasil em 1988 e a Colômbia em 1991, mediante a convocação de assembleias constituintes que se deram, em ambos os casos, de maneira pouco convencional. 
As semelhanças não param por aí. Ambos refundaram suas democracias sob premissas nas quais se autorreconheceram como países pluriétnicos e multiculturais (artigos 215 e 231 da Constituição brasileira e artigo $7^{\circ}$ da Constituição colombiana) e, assim, cedem à importância da participação popular e da implantação de direitos ditos de primeira, segunda e terceira gerações ${ }^{7}$ em suas cartas constitucionais, como fórmula padronizável de banimento do Estado autoritário, que até então conduzia suas trajetórias políticas (no Brasil uma ditadura militar; na Colômbia uma sucessão de golpes de Estado, intermediados por consecutivos estados de sítio).

Consideradas no que se assemelham, a Constituição da República Federativa do Brasil de 1988 e a Constituição Política da Colômbia, de 1991 (esta última, notadamente inspirada na primeira) são pródigas em demarcarem um extenso conjunto de direitos, num mesmo ato institucional, sem a correspondência de um processo histórico de conquistas.

Este fato, reconhecido e nominado de "curto-circuito histórico" (SANTOS, 2007, p. 26) por Boaventura de Sousa Santos, é característica compartilhada por ambas as realidades constitucionais, uma vez que o conjunto de direitos previstos não encontraram políticas públicas e sociais consolidadas que os garantam.

A Constituição brasileira é composta de duzentos e cinquenta artigos que se dividem em nove títulos. O Título II é aquele que versa sobre os “Direitos e Garantias Fundamentais" e, no Capítulo I, qual seja o que trata "Dos Direitos Individuais e Coletivos", estabelece, pelo artigo $5^{\circ}$ que todos são iguais perante a lei e, adiante, traz um rol de setenta e oito incisos, nos quais são listados direitos consagrados pela Carta Política brasileira como direitos e garantias fundamentais, de natureza individual ou coletiva.

Ao final do Capítulo I do Título II, o $\S 1^{\circ}$, do artigo $5^{\circ}$, da Constituição Federal do Brasil, afirma que, "as normas definidoras dos direitos e garantias fundamentais tem aplicação imediata" (BRASIL, 1988). Muito embora, nitidamente, tratando-se de previsão dotada de plasticidade, porque não define textualmente a localização tópica daqueles direitos em sua literalidade, tal prerrogativa favorece ao intérprete certa discricionariedade: ou a imediatidade lá prevista restringe-se às garantias individuais listadas no artigo $5^{\circ}$; ou ela abrange o conjunto

\footnotetext{
${ }^{7}$ Sobre a questão das gerações dos direitos, bastante lúcida é a lição de Antônio Escrivão Filho e José Geraldo de Sousa Júnior: "De fato, a teoria das gerações de direitos refere-se e talvez corresponda à história da Europa Ocidental em seu desenvolvimento social e político desde o advento da modernidade. Não nos parece, no entanto, que tal teoria e tais gerações possam ser afirmadas ou transportadas para a história e a realidade social e política da América Latina, senão em concepções que remontam, ainda que de modo inadvertido, às caravelas como metáfora de transporte, ou à colonialidade do saber como categoria analítica que emerge na teoria dos direitos humanos desde uma epistemologia do sul”. (ESCRIVÃO FILHO; SOUSA JÚNIOR, 2016, p. 37)
} 
de direitos fundamentais que vão se constituindo nos capítulos seguintes, a exemplo do Capítulo II, que trata dos Direitos Sociais, onde lá se acha inserido o direito à moradia.

Já a Constituição da Colômbia contém trezentos e setenta e nove artigos, divididos em treze títulos. O Título II é aquele que versa sobre "os direitos, as garantias e os deveres", cujo Capítulo I anuncia os direitos fundamentais, estes compreendidos entre o artigo 11 e o artigo 41 da referida Carta (COLÔMBIA, 1991).

Da mesma forma com que se procedeu no Brasil, a Colômbia trouxe expressamente em seu texto constitucional a proteção e aplicação imediata de direitos, fazendo-o no artigo $85^{8}$ (COLÔMBIA, 1991), contudo, diferentemente do Brasil, aquele dispositivo constitucional, ao determinar o emprego instantâneo de direitos considerados fundamentais, definiu-os prévia e explicitamente, de modo a estreitar a possibilidade de extensão daquela prerrogativa aos direitos sociais, econômicos e culturais, estes distintivamente fora do rol do artigo 85.

No caso do Brasil, manifesta-se o entendimento de que o alcance da norma contida no $\S 1^{\circ}$, do artigo $5^{\circ}$ da sua Constituição não se limita àqueles direitos previstos no dispositivo em que se acha topicamente inserido, mas abrange todo o conjunto de garantias, somando-se àquelas listadas no referido rol do artigo $5^{\circ}$ de seu texto, outras que detenham em seu conteúdo índole de fundamentalidade:

Para nós, o princípio da aplicabilidade imediata das normas definidoras dos direitos
fundamentais abrange todos os direitos fundamentais, até mesmo os não previstos no
catálogo Título II) e os não previstos na própria Constituição, desde que, quanto a
estes, ostentem a nota distintiva da fundamentalidade material (como os decorrentes
dos tratados internacionais em que o Brasil for signatário. Isto se dá não só porque o
art. $5^{\circ}, \S 1^{\circ}$ refere-se textualmente a direitos fundamentais - fazendo uso da fórmula
genérica "direitos e garantias fundamentais" - sem discriminá-los, mas também por
conta de uma interpretação sistemática e teleológica que venha a recair na análise da
referida disposição. (CUNHA JÚNIOR, 2016, p. 554)

Tomado o núcleo dos direitos fundamentais, sobretudo no caso da América Latina, no que tange à sua aplicabilidade imediata, é coerente que este seja pensado a partir da ideia de um projeto - um contrato fundador da modernidade, celebrado para proteger o homem das ações de seus semelhantes - que esquadrinha valores selecionados por dada sociedade: um acordo de agrupamento para a garantia de direitos.

Lênio Streck considera este um "ponto nodal na discussão sobre o papel da Constituição em países periféricos como o Brasil” (STRECK, 2014 p. 179), que deve ser

\footnotetext{
${ }^{8}$ Artículo 85. Son de aplicación inmediata los derechos consagrados en los artículos 11, 12, 13, 14, 15, 16, 17, 18, 19, 20, 21, 23, 24, 26, 27, 28, 29, 30, 31, 33, 34, 37 y 40. (COLÔMBIA, 1991)
}

Rev. de Direito Urbanístico, Cidade e Alteridade | e-ISSN: 2525-989X | Maranhão | v. 3 | n. 2 | p. 34 - 55 | Jul/Dez. 2017. 
compreendido como a manifestação do contrato social, a qual o autor chama de "refundação" de seu pacto:

\begin{abstract}
Mais do que assegurar os procedimentos da democracia - que são absolutamente relevantes -, é preciso entender a Constituição como algo substantivo, porque contém direitos fundamentais, sociais, coletivos que o pacto constituinte estabeleceu como passíveis de realização. Há que se deixar assentado que o constitucionalismo dirigente-compromissório não está esgotado. A Constituição ainda deve "constituira-ação", mormente porque no Brasil nunca constituiu. No texto da Constituição de 1988, há um núcleo essencial, não cumprido, contendo um conjunto de promessas da modernidade que deve ser resgatado (o ideal moral transforma-se em obrigação jurídica). (STRECK, 2014, p. 179)
\end{abstract}

Diferentemente do caso brasileiro, a Constituição da Colômbia - aqui claramente inspirada da constituição espanhola ${ }^{9}$ - preferiu trilhar o caminho da explicitação exaustiva do que conforma seu núcleo básico de aplicabilidade imediata. Neste sentido, aquele núcleo básico é preenchido por direitos mínimos, capazes de evidenciar a índole de um Estado Democrático de Direito e que deve ser compartilhada por todas as constituições que assim o instituam, deixando de curvarem-se às contingências peculiares de cada Estado.

O artigo 85 da Constituição Política da Colômbia esmiúça em seu conteúdo aqueles direitos fundamentais de aplicação imediata. No referido rol, em cujo conteúdo prevalecem os direitos civis e políticos, não estão listados os direitos sociais e econômicos, dentre estes, a política urbana e a função social da cidade.

Tal arranjo constitucional, tanto no caso do Brasil, quanto no caso da Colômbia, aponta para a necessidade de se discernir acerca da prevalência da função social da cidade no núcleo categorizado de direitos fundamentais autoaplicáveis ${ }^{10}$, ou, do contrário, sua consumação prática posta sob a dependência da atuação legislativa infraconstitucional.

\footnotetext{
9 “A Constituição espanhola de 1978, ao receber a influência do constitucionalismo alemão de pós-guerra, acolheu o conceito de direitos fundamentais que os associa à ideia de direitos fundantes da ordem social [...], derivado de valores superiores (justiça, igualdade e pluralismo) e do princípio de dignidade humana e, em razão disto, dotados de especiais dispositivos garantidores. [...] Assim, o constituinte de 1978 dedicou o título primeiro de sua obra a regular integralmente a Carta de direitos e deveres fundamentais [...]: d) Direitos sociais, econômicos e culturais (à saúde, à seguridade social, à moradia digna) e alguns direitos coletivos (ao meio ambiente são). A estes direitos de "segunda e terceira geração", nem sequer os denomina direitos, mas simplesmente "Princípios de orientação política, social e econômica"." (CHINCHILLA HERRERA, 2009, p. 126-127). (tradução nossa)

${ }^{10}$ Como ocurrió con los demás derechos económicos, sociales y culturales, desde sus primeros pronunciamientos, la jurisprudencia constitucional negó la iusfundamentalidad del derecho a la vivienda digna, señalando para el efecto, que se trata de un derecho de carácter prestacional cuyo contenido debe ser precisado en forma programática por las instancias del poder que han sido definidas con fundamento en el principio democrático, de conformidad con las condiciones jurídico materiales disponibles en cada momento histórico. (COLÔMBIA, 2011)
}

Rev. de Direito Urbanístico, Cidade e Alteridade | e-ISSN: 2525-989X | Maranhão | v. 3 | n. 2 | p. 34 - 55 | Jul/Dez. 2017. 
Tal discussão permite distinguir o importante papel da política urbana de ambos os países, bem como e em que medida o tratamento constitucional dado a este conjunto de direitos, nas duas realidades, é capaz de alcançar a função social da cidade.

\section{FUNÇÃO SOCIAL DA CIDADE NAS CONSTITUIÇÕES DO BRASIL E DA COLÔMBIA}

Dialogando com os desafios da questão urbana, tem-se a função social da cidade como um princípio qualificante do direito social à moradia urbana, que deve ser pensado a partir de paradigmas constitucionais contemporâneos, por meio dos quais será possível problematizar a questão da democratização dos territórios.

Categoriza-se, portanto, o direito à cidade como um direito à reivindicação de "um tipo de poder configurador sobre os processos de urbanização" (HARVEY, 2014, p.30), que envolve, dentre outras coisas, a criação de formas jurídicas que possam evitar, ou mesmo amortecer, a vocação segregacionista do poder econômico e seus efeitos sobre o crescimento urbano. Neste contexto, eis que demostrada a importância da discussão acerca da função social da cidade, no que tange à sua inserção na realidade constitucional da América do Sul, aqui especialmente, nos casos do Brasil e da Colômbia.

Reconhecido como um direito humano pela Declaração Universal dos Direitos do Homem, de 1948, o direito à moradia passou a integrar o texto constitucional brasileiro a partir da emenda constitucional $\mathrm{n}^{\circ} 26$, de 14 de fevereiro de 2000, doravante passando a ser abrigado como um direito social, previsto no artigo 6º da Constituição Federal de 1988.

O legislador constitucional brasileiro, sistematizando os direitos que convergem para o direito à moradia, o fez no Título VII, do texto da Constituição Federal, ao tratar da Ordem Econômica e Financeira, Capítulo II, inscrevendo constitucionalmente as regras sobre a Política Urbana que, examinadas, especialmente no artigo 182, lá se veem consignadas as funções sociais da cidade, reflexo de uma garantia social, a guisa de baliza posta para a realização do desenvolvimento do país.

A Constituição Federal do Brasil categoriza, no artigo 182, a título de política de desenvolvimento urbano, o incremento das funções sociais da cidade, deixando clara sua intenção política de pensar o urbano a partir da pluralidade de premissas principiológicas 
decorrentes da dignidade da pessoa humana, quando enquadra aquela função à garantia do bemestar da coletividade.

Portanto, preencher de conteúdo a função social da cidade, no âmbito da Constituição brasileira, passa, necessariamente, pela constatação de que a mesma revela uma proposta progressista e humanista do legislador constituinte: "o direito à cidade é um significante vazio, repleto de possiblidades imanentes, mas não transcendentes" (HARVEY, 2014, p.244). Tratase de um conceito que, uma vez balizado pela realização de direitos fundamentais, sobretudo àqueles mais relacionados à cidade, requer, para sua significação, a manutenção da capacidade de todos os habitantes de uma cidade de manterem condições apropriadas de vida urbana: "Esta é uma condição que exige organização de toda a cidade e uma resposta política de toda a cidade" (HARVEY, 2014, p.119).

A realização plena da função social da cidade encontra o desafio de maximização dos bens comuns, em detrimento de sua apropriação pelo mercado e a lógica moderna de produção de valor, ligada a indicadores que norteiam o limite liberal do individualismo proprietário lockeano (MESA CUADROS, 2013), quais sejam o trabalho e a propriedade.

As reflexões do economista Amartya Sen (2008) acerca da necessidade de proteção aos bens públicos, como aqueles que permitem indiscriminadamente condições apropriadas de vida urbana, ajudam a dotar de conteúdo a previsão constitucional da função social da cidade:

\footnotetext{
Uma das suposições tradicionalmente feitas para demonstrar a eficiência do mecanismo de mercado é a de que todo bem - e, de um modo mais geral, tudo aquilo que o nosso bem-estar depende - pode ser comprado e vendido no mercado. Tudo se pode comercializar (se quisermos colocar no mercado), e não existe nenhuma influência que seja "não-negociável e significativa sobre nosso bem-estar. Na verdade, porém, alguns dos mais importantes elementos que contribuem para a capacidade humana podem ser difíceis de vender exclusivamente para uma pessoa de cada vez. Isso se aplica em especial quando consideramos os chamados bens públicos, que as pessoas consomem juntas, e não separadamente. (SEN, 2008, p. 153)
}

Daí define-se que, os direitos que manifestam substancialmente um bem-estar coletivo no ambiente urbano são aqueles que, para efeito de realizarem a função social da cidade, demandam que sejam usufruídos comunitariamente: "Todos aqueles cujo trabalho está envolvido em produzir e reproduzir a cidade tem um direito coletivo não apenas àquilo que produzem, mas também de decidir que tipo de urbanismo deve ser produzido, onde e como" (HARVEY, 2014, p.245).

Em simetria com a previsão constitucional da função social da cidade, o Brasil elaborou o Estatuto da Cidade, Lei 10.257, de 10 de julho de 2001, por via do qual o direito à 
cidade ingressou, ao menos formalmente, no arcabouço político-normativo brasileiro, inserindo a perspectiva de uma gestão democrática da cidade, com a participação popular e a regularização fundiária a constituírem diretrizes para as políticas públicas voltadas para o direito de ter uma moradia digna, e os respectivos instrumentos jurídicos fundantes desta realidade.

De fato, o Estatuto da Cidade permitiu com que a função social da cidade ingressasse definitivamente na pauta dos debates acerca da materialização dos direitos sociais e as dificuldades inerentes a sua expansão: “eles podem estar na Carta de 1988, mas não se traduzem no fortalecimento de um campo institucional de negociação de interesses, [...] e nem em políticas sociais de alcance massivo" (KOWARICK, 2009, p. 77).

A função social da cidade no Brasil, primeiramente anunciada pela Constituição Federal de 1988, e depois esquematizada no Estatuto da Cidade, Lei 10.257, de 10 de julho de 2001, encontra neste último suas diretrizes e sua objetivação, especialmente no teor do artigo $2^{\circ}$, que em seu âmbito traça diretrizes gerais a serem seguidas no campo das cidades:

Estas diretrizes dizem respeito: ao planejamento urbano, em todas as esferas governamentais (incs. I a IV); instrumentos específicos (incs. V e VI), voltados ao cumprimento de certos objetivos urbanísticos (inc. VI e respectivas alíneas), à preocupação com a expansão urbanística de forma democrática, integrada e sustentável, com a distribuição isonômica do solo e das facilidades propiciadas pelo ambiente urbano (incs. VII a IX e XII a XV); aspectos pertinentes à ordem financeira e tributária (inc. X). (ALVIM, 2014, p. 37)

Sucede que, na experiência do Brasil, a norma (tanto a Constituição Federal, quanto o Estatuto da Cidade) conferiu ao poder público municipal a atribuição de ordenação e desenvolvimento da função social da cidade, cabendo a este último definitivamente, a tarefa de enfrentar as demandas urbanas através de regras que devem estar inseridas em seus respectivos Planos Diretores, doravante a serem elaborados segundo as diretrizes do Estatuto da Cidade.

\footnotetext{
Os instrumentos da política urbana relacionados na lei brasileira são aplicáveis, predominantemente, no nível municipal [...]. Conforme já destacado, a maior parte desses instrumentos são regidos por legislação própria [...]. Dadas as exigências burocráticas e os prazos para que esses instrumentos possam ser implementados e considerando ainda que um PD [Plano Diretor] e lei complementar devem preceder e orientar sua aplicação, podemos concluir que as medidas, tais como estão previstas na lei (decorrente do texto da Constituição Federal) não permitem respostas rápidas aos problemas urbanos atuais. (MARICATO, 2013, p. 105-107)
}

Longe de descaracterizar a importância do Estatuto da Cidade como significativo instrumento para a demarcação da questão urbana no Brasil e sua distinção jurídico-normativa, bem como a formal inscrição de sua agenda na pauta das políticas públicas, não se pode deixar 
de pontuar que, no que tange à função social da cidade, este conjunto de dispositivos se perfaz esvaziado de poder coercitivo, uma vez que endereça ao ente municipal a definição do conteúdo daquela garantia:

A solução dada pela $\mathrm{CF}$ e pelo Estatuto da Cidade para a realização e desenvolvimento da política urbana foi a planificada, ou seja, a concretizada por planos, projetos, a partir da própria percepção de cada local, vinculada com a paisagem real, a diversidade do povo e dos espaços urbanos [...]. (SANTOS, 2014, p. 571)

Esta configuração faz criar, no âmbito da realidade urbana do Brasil, uma espécie de desagregação, uma vez que o enfrentamento da questão urbana e os problemas dela decorrentes não são confrontados de maneira uniforme, porquanto sujeitam as cidades a uma espécie de determinismo vinculado ao desempenho e às contingências de seus respectivos planos diretores, restando à reivindicação da função social da cidade sujeita ao que Milton Santos (2012) chama de "especialização funcional":

\footnotetext{
Essa especialização existe praticamente apenas nos locais de exportação e de valorização dos recursos naturais. Mas, nesse caso, trata-se de uma especialização ligada a uma vantagem particular que atrai capitais externos, não estando ligada ao crescimento próprio da cidade. Deixando de lado esse caso, essencialmente excepcional, as atividades não se apresentam sob forma unitária especializada, mas arranjadas em um complexo industrial que compreende vários ramos de produção. Excetuando a importância da economia de escala que permite, bem como o quase monopólio exercido em matéria de equipamentos e infraestrutura, a cidade é o lugar de eleição dessas zonas industriais polifuncionais. (SANTOS, 2012, p. 132-133)
}

A lúcida compreensão deste iminente geógrafo brasileiro vem em socorro das ideias aqui trabalhadas, quando observa a intrínseca relação existente entre o desenvolvimento urbano e o desenvolvimento industrial, que afinados em proporção direta, influenciam sobremaneira a administração pública municipal, no que tange ao conteúdo mais ou menos elitista de sua política urbana e à aplicação estratégica de seu plano diretor.

Assim, as disposições escritas atinentes à função social da cidade, embora sejam verdadeiras conquistas, estão ainda à mercê das descontinuidades geradas pela desigual distribuição de riqueza (realidade da América Latina), pelas prioridades do mercado e pela concentração de renda como fator determinante da realidade urbana brasileira, pelo que frustradas em suas respectivas intenções humanísticas.

Tome-se como exemplo o caso da cidade de Curitiba, capital do Paraná, Estado da região sul do Brasil, premiada por seu perfil urbano de característica vanguardisticamente sustentável. Sua tecnologia urbana é fruto de um processo de "saneamento ambiental, embelezamento e segregação territorial” (MARICATO, 2013, p. 17): 
Visto deste ângulo, o que seria a experiência de Curitiba senão o chamado planejamento estratégico dos anos 90 no qual, em torno de um projeto comum de cidade, transformado em "pátria, empresa e mercadoria" (VAINER, 2000), é proposto um pacto social com base no "desenvolvimento urbano" e nos interesses do capital? [...], a experiência de Curitiba antecipa o debate que será travado no âmbito do próprio país, com o desembarque aqui da corrente ideológica do neoliberalismo e que tem na negação da política e no escamotear da diferença das classes sociais seu sentido maior. (BURNETT, p. 178-180, 2009)

São realidades que determinam uma diferenciação regional no que tange à urbanização dos países periféricos, como é o caso do Brasil, que, na visão de Milton Santos (2012), resulta não de um processo de acumulação, mas de um processo "explosivo, mais localizado, seletivo e, por isso mesmo, criador de descontinuidades. Isso explica as diferenças tanto no espaço nacional e regional, como no interior das cidades" (SANTOS, 2012, p. 106).

Diferenciação regional de igual proporção também é diagnosticada na paisagem urbana da Colômbia:

É o caso de Antioquia (Colômbia), que em 1967 concentrava 93\% dos artigos têxteis de algodão produzido pela indústria colombiana; $82 \%$ dos discos; $62 \%$ dos artigos de cerâmica; 59\% dos aparelhos eletrodomésticos; $46 \%$ das tintas; $37 \%$ do equipamento industrial (máquinas); $30 \%$ das roupas masculinas; $28 \%$ do cimento e $23 \%$ dos artigos de alumínio. (SANTOS, 2012, p. 133)

O acúmulo destas atividades industriais naquela região tem, em Medellín, seu maior exponencial. Capital da Província de Antióquia, situada no noroeste da Colômbia, aquela cidade tem se constituído, a exemplo de Curitiba no Brasil, referência mundial na condução do processo de reconfiguração das políticas urbanas de planejamento e gestão da cidade real ${ }^{11}$, e sua experiência faz-se bastante operativa para a construção de uma imagem da ideia de desigualdade nos indicadores constitucionais da função social da cidade, ora aqui trabalhados.

De fato, o constitucionalismo na Colômbia, assim como no Brasil, claramente faz a opção por consignar textualmente um extenso rol de direitos, porquanto inscrevendo os direitos fundamentais entre os artigos 11 a 41 e os direitos econômicos, sociais e culturais entre os artigos 42 a 77.

\footnotetext{
${ }^{11}$ Quanto à percepção da "cidade real", Raquel Rolnik trabalha este conceito a partir de uma dimensão de padronização da cidade, legitimada e planejada pelas instâncias normalizadoras do Estado: "Assim, ao mesmo tempo em que para os equipamentos de saúde há o indivíduo saudável, para a legislação urbana há a casa saudável, o bairro saudável. As casas e bairros de nossas cidades podem ser construídos se obedecerem a certo padrão, completamente adaptado à ocupação capitalista da terra e à micropolítica familiar burguesa. A reprodução infinita do projeto-padrão na cidade, reforça a norma. Assim, para o planejamento urbano, as favelas e áreas de invasão, assim como os cortiços e os quintais, são habitações subnormais. Geralmente o que o planejamento urbano chama de subnormal, a polícia chama de marginal e o povo em geral de má vizinhança, que desvaloriza o bairro". (ROLNIK, 2014, p. 13)
} 
A Constituição Política da Colômbia, de 1991, de modo semelhante à brasileira, com o propósito de pactuar a instituição de um Estado de Direito, construído mediante um processo de redemocratização, mobiliza o direito à moradia digna e a função social da propriedade em seus artigos 51 e 58, respectivamente, para vinculá-las a implicações obrigacionais que preenchem de conteúdo a função social da cidade e, a partir daquele marco, atrelou à sua política urbana à Lei no 388/97 (Lei de Desenvolvimento Territorial), onde foram fixadas as diretrizes para a gestão urbana no país.

No que diz respeito à política urbana, a Colômbia aprovou duas leis muito importantes nas décadas de 80 e 90, a saber, a Lei de Reforma Urbana (Lei $9^{a}$ de 1989), ainda em um momento anterior à promulgação da Constituição de 1991, e a Lei de Desenvolvimento Territorial (Lei 388 de 1997). Estas leis, que demandaram anos de discussões e a mobilização de diferentes atores sociais, inovaram a agenda da política urbana no país, estabelecendo um elenco de instrumentos e princípios orientadores para o planejamento urbano e a gestão urbanística das cidades colombianas. Os princípios indicados pela lei 388/97 para o ordenamento do território urbano colombiano, adotam como bússola do desenvolvimento urbano o primado dos interesses coletivos sobre os interesses individuais dos proprietários urbanos; a função social e ecológica da propriedade e a distribuição equitativa das cargas e benefícios da urbanização. (ALFONSIN, p. 169, 2008)

Esta lei, cuja função foi a de estabelecer parâmetros para o planejamento urbano na Colômbia, assim como o Estatuto da Cidade faz no Brasil, endereça aos municípios a tarefa de gerenciar as estratégias urbanísticas definidas pelos instrumentos contidos em seu texto, que deverão fazê-lo, segundo Alfonsin (2008), a partir da elaboração de um Plano de Ordenamento Territorial (POT), componente chave para a concretização das políticas urbanas (como o Brasil, que estabeleceu o sistema dos Planos Diretores, em sua Constituição Federal e no Estatuto da Cidade):

\begin{abstract}
Além disso, a lei se notabiliza pelo destacado papel conferido ao poder público municipal para regular os mercados de solo urbano e garantir um desenvolvimento urbano orientado pelo planejamento municipal, a partir do reconhecimento de que o urbanismo é uma função pública. Como técnica de Planejamento Urbano, a lei 388/97 adotou um sistema de planos em cascata (MALDONADO et al, 2006), tendo na figura do Plano de Ordenamento Territorial - P.O.T. a peça legal de articulação de todo o sistema de planejamento urbano. Esses planos têm funções claramente definidas pela lei e que vão mais além de uma mera ordenação do território que sirva de indicador ao mercado imobiliário. (ALFONSIN, p. 168-169, 2008)
\end{abstract}

Com população de quase 49 milhões de habitantes, a Colômbia apresenta índices oficiais de $27,8 \%$ de seus habitantes vivendo na pobreza e $7,9 \%$, na pobreza extrema ${ }^{12}$, e,

\footnotetext{
${ }^{12}$ Dados encontrados no sítio eletrônico do Departamento Administrativo Nacional de Estadística de Colombia. Disponível em: <dhttps://www.dane.gov.co/index.php/estadisticas-por-tema/pobreza-y-condiciones-devida/pobreza-y-desigualdad $>$.
} 
segundo dados do Banco Interamericano de Desenvolvimento, 37\% de suas famílias são semteto, ou residem em moradias inadequadas ${ }^{13}$. São números muito aproximados aos do Brasil que, com uma população de quase 207 milhões de habitantes, 9,2\% vivem abaixo da linha da pobreza, segundo dados do $\operatorname{IBGE}^{14}$ e, conforme pesquisa empreendida pelo Banco Interamericano de Desenvolvimento, 33\% de suas famílias são sem-teto, ou residem em moradias inadequadas ${ }^{15}$.

Esta realidade revela que os Planos Diretores ou Planos de Ordenamento Territorial, embora constituam um avanço legislativo no âmbito das políticas urbanas tanto no Brasil, quanto na Colômbia, não têm mostrado suficiência para abarcar a fragilidade da política urbana de ambos os países, isto porque não podem abordar de forma planificada realidades sociais distintas, marcadas pela desarticulação de grande parte da população e de sua paisagem urbana em relação às ficções do mercado:

Definitivamente, não há uma só Colômbia: existem duas Colômbias. A Colômbia
urbanizada, feita por cidades como Bogotá, Medellín e Cali e Bucaramanga na Região
Andina e Barranquilla; é Colômbia moderna, em condições de poder se integrar às
novas correntes econômicas e culturais da globalização, e é a outra Colômbia a dos
colonos, camponesas, indígenas, e negros, na qual proliferam cultivos ilícitos, a
pecuária extensiva e a violência de mil faces que gera o drama dos refugiados internos.
Esta Colômbia em que agentes para-estatais disputam o território pelo controle de
rotas e da coca e dos recursos tanto naturais quanto públicos ante a ausência total do
Estado. (IBARRA LOZANO, p. 44, 2007) (tradução nossa)

A transcrição acima reflete o arquétipo da desigualdade de urbanização da Colômbia, que semelhantemente ao Brasil, apresenta câmbios demográficos e de desenvolvimento das cidades, num padrão regional extremamente contraditório e pouco integrado entre si, estimulador de um processo de migração aos grandes centros urbanos, que com isto finda por agudizar o problema das funções sociais da cidade nos dois países.

Amolda-se, por conseguinte, um ponto de interseção entre os dois sistemas jurídicoconstitucionais, qual seja a identificação da função social da cidade como um direito de caráter fundamental e de urgência, levando-se em conta o contingente histórico da América Latina,

\footnotetext{
13 Dados encontrados no sítio eletrônico do Banco Interamericano de Desenvolvimento. Disponível em <http://www.iadb.org/pt/noticias/comunicados-de-imprensa/2012-05-14/deficit-habitacional-na-america-latinae-caribe,9978.html 14/05/2012

${ }^{14}$ Dados encontrados no sítio eletrônico do Instituto Brasileiro de Geografia e Estatística. Disponível em: < http://www.ibge.gov.br/home>.

15 Dados encontrados no sítio eletrônico do Banco Interamericano de Desenvolvimento. Disponível em $<$ http://www.iadb.org/pt/noticias/comunicados-de-imprensa/2012-05-14/deficit-habitacional-na-america-latinae-caribe,9978.html 14/05/2012>.
}

Rev. de Direito Urbanístico, Cidade e Alteridade | e-ISSN: 2525-989X | Maranhão | v. 3 | n. 2 | p. 34 - 55 | Jul/Dez. 2017. 
bem como o problema relacionado à efetividade daquele direito no combate à pobreza, à desfiliação urbana e às novas questões sociais que neste âmbito se evidenciam.

\section{CONSIDERÇÕES FINAIS}

O contexto político do Brasil e a Colômbia tem em comum o fato de terem promovido um novo pacto constitucional formulado a partir da necessidade de legitimação de uma nova perspectiva democrática de desenvolvimento, razão pela qual optaram pelo esmiuçamento hierarquizado das regras fundantes de suas ordens jurídicas.

Sucede que os direitos econômicos, sociais e culturais, dentre os quais aqueles nos quais se acha inscrita a função social da cidade, destarte inseridos na Constituição colombiana, bem como na brasileira, juntamente com os direitos civis e políticos, espraiam-se numa espécie de teia que resulta de um processo de empoderamento da América Latina, e decorre, seminalmente, de sua trajetória histórica e das necessidades acumuladas ao longo dos séculos em que esteve, ao menos formalmente, sob o domínio das metrópoles europeias.

Por esta lógica é possível definir a tradução mercantil dos espaços urbanos e sua explicação feita pela pauta de uma gestão que os categorize como mercadorias a serem adquiridas. Esta visão, amplamente disseminada na América Latina, fortalece-se em detrimento de uma compreensão das funções sociais da cidade a lhe dar um sentido de identidade coletiva.

No início deste trabalho, questionou-se se as políticas urbanas teriam por função a de conceder "satisfações" ao contingente humano das cidades a fim de que estes pudessem conviver com a financeirização dos direitos fundamentais.

Distinguindo os modelos constitucionais do Brasil e da Colômbia, compreendeu-se que ambos os ordenamentos jurídicos apresentam distinções meramente acidentais quanto à previsão material de exequibilidade dos direitos fundamentais. A plasticidade do $\S 1^{\circ}$, do artigo $5^{\circ}$, da Constituição Federal do Brasil, aparentemente distinta da configuração limitadora do artigo 85 da Constituição Política da Colômbia, longe de colocar aquelas duas realidades em oposição, pelo contrário, inserem-nas na trama de uma vacância interpretativa acerca da força normativo-constitucional da função social da cidade a constranger o poder público administrativo. 


\section{REFERÊNCIAS}

ALFONSIN, Betânia de Moraes. A Política Urbana em disputa: desafios para a efetividade de novos instrumentos em uma perspectiva analítica de Direito Urbanístico Comparado (Brasil, Colômbia e Espanha). 2008. 265 f. Tese (Doutorado em Planejamento Urbano e Regional) Programa de Pós-Graduação em em Planejamento Urbano e Regional da Universidade Federal do Rio de Janeiro - UFRJ, Rio de Janeiro, 2008.

ALVIM, Arruda. A Função Social da Propriedade e da Posse. In: Estatuto da Cidade. São Paulo: Editora Revista dos Tribunais, 2014.

BID. Banco Interamericano de Desenvolvimento. Estudo do BID revela que América Latina e o Caribe enfrentam um déficit de habitação considerável e crescente. 14/05/2012. Disponível em <http://www.iadb.org/pt/noticias/comunicados-de-imprensa/2012-05-14/deficithabitacional-na-america-latina-e-caribe,9978.html 14/05/2012>. Acesso em 04.dez.2016.

BORJA, Jordi. La Ciudad Conquistada. Madrid: Alianza Editorial, 2003.

BRASIL. Constituição (1988). Constituição da República Federativa do Brasil. Brasília: Senado, 2009.

Estatuto da Cidade. Lei $\mathrm{n}^{\circ}$ 10.257, de 10 de julho de 2001. Disponível em <

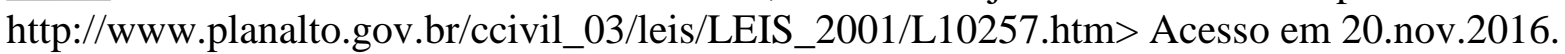

BURNETT, Frederico Lago. Da Tragédia Urbana à Farsa do Urbanismo Reformista: A Fetichização dos Planos Diretores Participativos. 2009. 528 f. Tese (Doutorado em Políticas Públicas) - Programa de Pós-Graduação em Políticas Públicas da Universidade Federal do Maranhão, São Luís, 2009.

CASTEL, Robert. As metamorfoses da questão social. Petrópolis: Vozes, 1998.

CHINCHILLA HERRERA, Tulio Elí. ¿Qué son y cuáles son los Derechos Fundamentales?”. Bogotá: Editorial Temis, 2009.

COLÔMBIA. Constituição (1991). Constituição Política da Colômbia. Disponível em: < http://www.corteconstitucional.gov.co/inicio/Constitucion\%20politica\%20de\%20Colombia\% 20-\%202015.pdf>. Acesso em 26.nov.2016.

Disponível

Ministerio de Viviendas. Colombia: cien años de politicas habitacionales. 2014.

http://www.minvivienda.gov.co/Documents/100anosdepoliticashabitacionales.pdf. Acesso em 08/08/2017.

CUNHA JÚNIOR, Dirley. Curso de Direito Constitucional. $10^{\mathrm{a}}$ ed. Salvador: JusPODIVM, 2016.

DANE. Departamento Administrativo Nacional de Estadística de Colombia. Colômbia, 2015.

Rev. de Direito Urbanístico, Cidade e Alteridade | e-ISSN: 2525-989X | Maranhão | v. 3 | n. 2 | p. 34 - 55 | Jul/Dez. 2017. 
Disponível em: <dhttps://www.dane.gov.co/index.php/estadisticas-por-tema/pobreza-ycondiciones-de-vida/pobreza-y-desigualdad>. Acesso em 04.dez.2016.

ESCRIVÃO FILHO, Antônio; SOUSA JÚNIOR, José Geraldo de. Para um debate teóricoconceitual e político sobre os direitos humanos. Editora D’Plácido, 2016.

GEHL, Jan. Cidades Para Pessoas. $3^{\text {a }}$ ed. São Paulo: Perpectiva, 2015.

HARVEY, David. Cidades Rebeldes: Do direito à cidade à revolução urbana. São Paulo: Martins Fontes, 2014.

IBARRA LOZANO, Jairo. Reflexiones sobre el ordenamiento territorial en Colombia. Justicia Juris, ISSN 1692-8571, Vol 7. Abril-Septiembre 2007, p. 37-45. Disponível em: < https://www.uac.edu.co/images/stories/publicaciones/revistas_cientificas/juris/volumen-4-no7/art-5.pdf>. Acesso em: 04.dez.2016.

IBGE. Instituto Brasileiro de Geografia e Estatística. Disponível em: < http://www.ibge.gov.br/home>. Acesso em 04.dez.2016.

KOWARICK, Lúcio. Viver em Risco: sobre a vulnerabilidade socioeconômica e civil. São Paulo: Ed. 34, 2009.

LEFEBVRE, Henri. O Direito à Cidade. São Paulo: Centauro Editora, 2011.

LISTA DE PAÍSES DA AMÉRICA DO SUL POR POPULAÇÃO. n.d. In: WIKIPÉDIA: a enciclopédia livre. Wikimedia, 2017. Disponível em: $<$ https://pt.wikipedia.org/wiki/Lista_de_pa\%C3\%ADses_da_Am\%C3\%A9rica_do_Sul_por_p opula $\% \mathrm{C} 3 \% \mathrm{~A} 7 \% \mathrm{C} 3 \% \mathrm{~A} 3 \mathrm{o}>$. Acesso em: 10.08.2017.

MARICATO, Ermínia. Brasil, cidades: alternativas para uma crise urbana. Petrópolis: Vozes, 2013.

. O impasse da política urbana no Brasil. Petrópolis: Vozes, 2014.

MESA CUADROS, Gregório. Derechos ambientales en la perspectiva de integralidad: Concepto y fundamentacion de nuevas demandas y resistências actuales hacia el "Estado ambiental de derecho". $3^{a}$ ed. Bogotá: Universidad Nacional de Colombia. Faculdad de Derecho, Ciencias Políticas y Sociales, 2013.

ORGANIZAÇÃO DAS NAÇÕES UNIDAS. Declaração Universal dos Direitos do Homem. 10 de dezembro de 1948. Disponível em $<$ https://nacoesunidas.org/> Acesso em 29.jul.2016.

PEGORARO, L; RINELLA, A. Introducción al Derecho Constitucional Comparado. IIJUNAM. 2006. Disponível em: <https://biblio.juridicas.unam.mx/bjv/detalle-libro/1832introduccion-al-derecho-publico-comparado>. Acesso em 19.nov.2016.

ROLNIK, Raquel. O que é cidade. $4^{\mathrm{a}}$ ed. São Paulo: Ed. Brasiliense, 2012.

Rev. de Direito Urbanístico, Cidade e Alteridade | e-ISSN: 2525-989X | Maranhão | v. 3 | n. 2 | p. 34 - 55 | Jul/Dez. 2017. 
. Guerra dos Lugares: a colonização da terra e da moradia na era das finanças. São Paulo: Boitempo, 2015.

ROULAND, Norbert. Nos Confins do Direito. São Paulo: Martins Fontes, 2008.

SANTOS, Boaventura de Sousa. Para uma Revolução Democrática da Justiça. São Paulo: Cortez, 2007.

SANTOS, Juliana Cavalcante dos. A Função Social da Propriedade Urbana e Estatuto da Cidade. In: Estatuto da Cidade. São Paulo: Editora Revista dos Tribunais, 2014.

SANTOS, Milton. A Urbanização Desigual. São Paulo: Editora da universidade de São Paulo, 2012.

SEN, Amartya. Desenvolvimento como Liberdade. São Paulo: Companhia das Letras, 2008.

SHAPIRO, Mario. Judicial review in developed democracies. In: GLOPPEN, Siri; GARGARELLA, Roberto; SKAAR, Elin (Coords). Democratization and the Judiciary: the accountability function of Courts in new democracies. London; Portland: Frank Class Publishers, 2004.

STRECK, Lênio Luiz. Verdade e Consenso: Constituição, hermenêutica e teorias discursivas. $5^{\text {a }}$ ed. São Paulo: Saraiva, 2014. 